\title{
RESENHA DE: "VISÕES DA IDADE MÉDIA", DE RICARDO DA COSTA, POR NATASHA MATEUS
}

\section{Review of "Visions of the Middle Ages", from Ricardo da Costa, by Natasha Mateus}

Natasha Nickolly Alhadef Sampaio Mateus ${ }^{1}$ PPGHIS-UFMA-FAPEMA ORCID: https://orcid.org/0000-0002-9634-665X E-mail: natasha_alhadef@hotmail.com

Recebido em: 20/08/2020 Aprovado em: 12/01/2021

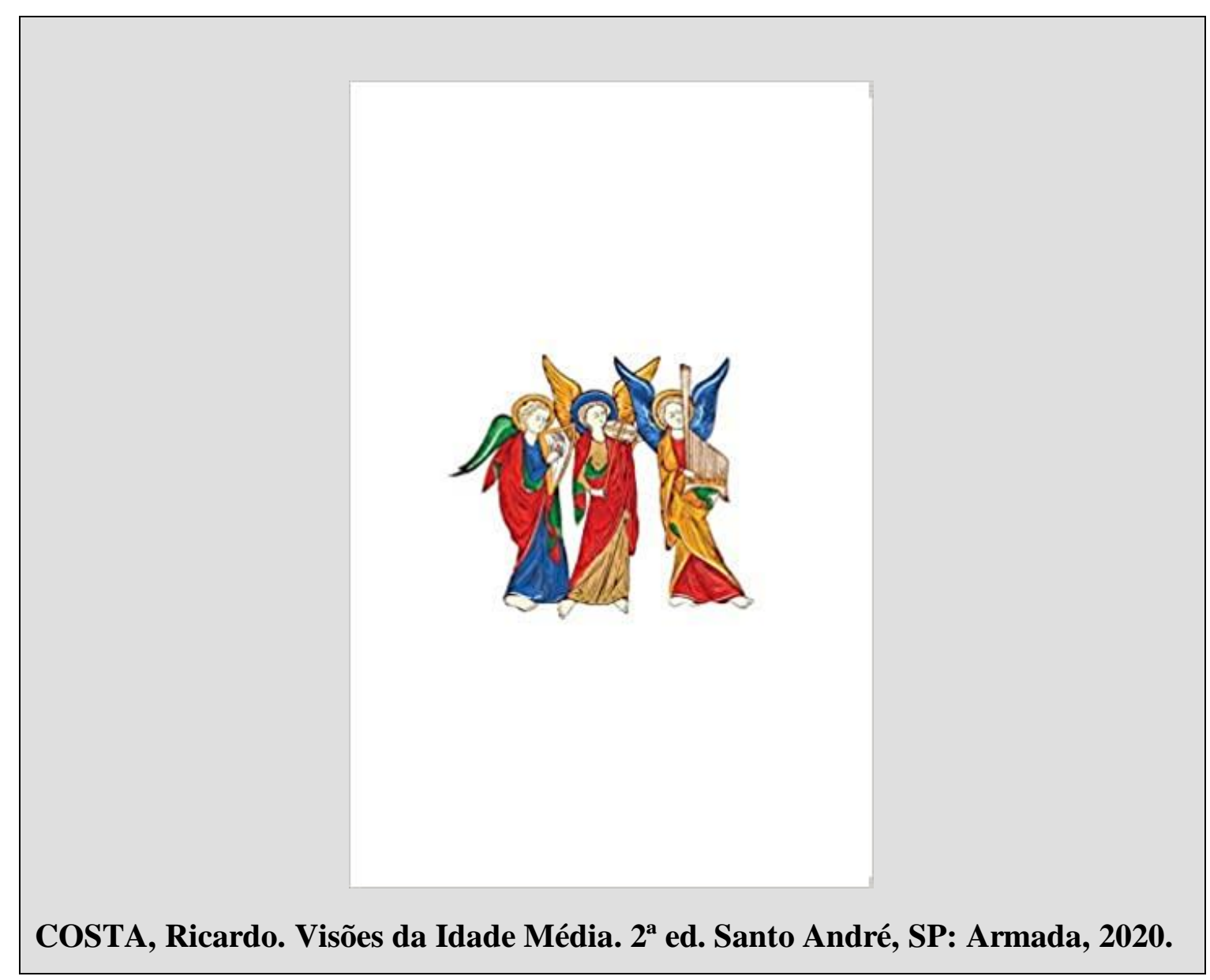


Ricardo da Costa é historiador e trabalha com diversos temas sobre o passado e o presente da humanidade. Especialista em História Medieval, publicou mais de cem trabalhos, originalmente em revistas especializadas no Brasil, assim como no exterior. Formou-se em História, na Universidade Estácio de Sá, e tem Mestrado e Doutorado pela Universidade Federal Fluminense (UFF). Atualmente, é Professor Titular do Departamento de Teoria da Arte e Música da Universidade Federal do Espírito Santo (UFES). É conhecido, sobretudo, por seus estudos acerca de Ramon Llull, tendo traduzido para o português diversas obras do filósofo catalão, o que possibilitou conhecer um pouco mais a respeito desse mundo medieval.

Em Visões da Idade Média, o (a) leitor (a) encontrará bem mais do que artigos, mas entrará em contato com as temáticas do medievo existentes nas fontes históricas, sob a ótica de um historiador, que tem se dedicado há muitos anos ao fortalecimento dos estudos medievais no Brasil. Costa dá vida às fontes pesquisadas e interpretadas, em que enchendo o leitor de curiosidade e questionamento. Cada capítulo mostra uma parcela do mundo medieval, embora não haja ali um enaltecimento do período, almejase na obra desmistificar os conceitos e interpretações equivocadas em relação à Idade Média. Trata-se de um livro instigante, que em suas mais de duzentas páginas brinda o (a) leitor (a) com uma escrita agradável e estimulante.

O livro Visões da Idade Média aborda de maneira interdisciplinar a História, a Literatura, a Filosofia e a Artes. Cada seção contém três artigos, exceto a última secção que consta quatro textos, sobre essas áreas cuja a leitura (sem esgotá-las) conduz-nos a reflexões críticas. Entre eles, há um artigo inédito escrito em coautoria com o Dr. Milton Gustavo Vasconcelos, o qual versa sobre a Inquisição, isto é, tema que, embora já muito comentado e analisado, mostrou-se passivo de interpretações questionáveis, que o apresentavam como uma espécie de resumo da Idade Média.

Neste sentido, o autor traz sua interpretação sobre a Idade Média, indo na contramão de distorções não apenas naturalizadas acerca desse período, mas por vezes aprendidas erroneamente. Trata-se de um período de mil anos, com uma variada história política, cultural, social, econômica que está presente, seja na Europa, seja nas possíveis raízes medievais observadas na história do Brasil (FRANCO JÚNIOR, 2001). Como afirma Marc Bloch, a história não é uma relojoaria, mas “[...] um esforço para um melhor conhecer uma coisa em movimento" (BLOCH, 1965, p. 29). 
O texto de abertura é provocativo, porque os autores desfazem alguns mitos a respeito da Inquisição bastante cristalizados no imaginário popular. Iniciam o prólogo, em tom de brincadeira, por meio de um diálogo fictício. Nessa "conversa", Costa e Vasconcelos são questionados por um sobre veracidade da pesquisa, e os autores prometem dizer apenas a "verdade" sobre a Inquisição. Assim, despertam no (a) leitor (a) a curiosidade de imaginar cada cena descrita no texto, pois, são analisadas com precisão de detalhes, o que torna o texto agradável e imaginativo.

$\mathrm{Na}$ seção História, o autor lança uma provocação, ao intitular um de seus capítulos Para que serve a História? Para nada..., através de tal indagação, não somente prende a atenção do (a) leitor (a), mas já o (a) induz a uma possível resposta. Ainda neste capítulo, Costa narra suas experiências pessoais como docente, na tentativa de responder o porquê de estudar essa disciplina tão questionada.

No mesmo capítulo, Ricardo da Costa, diz que a História possui uma grande divergência no que tange às teorias e métodos, pois não haveria um consenso sobre "a razão de ser" dessa disciplina. Para isso, lança mão de sete perguntas, ou melhor, "sete perguntas, ou melhor, sete respostas para sete perguntas criam esse impasse" (p. 64) nas palavras do autor. Em seguida, apresenta seu ponto de vista acerca desse impasse e infere que o "passado não tem relação (nem culpa) com nossas propostas utópicas de futuro. Para termos uma proposta de futuro, não é preciso conhecer o passado. Basta sonhar" (p.72).

O autor cita o historiador Eric Hobsbawm, ao destacar que atualmente a História é "revista ou inventada por gente que não deseja o passado real, mas somente um passado que sirva aos seus objetivos" (p. 72). Para Costa, esse é um ponto muito interessante, pois é defensor de que há um equívoco no uso do passado para a justificativa de uma visão de mundo.

Conclui este capítulo, afirmando que, se o conhecimento histórico não tiver como finalidade tornar melhor os indivíduos e suas relações, sua serventia será apenas de "acirrar conflitos e aumentar conflitos e aumentar a violência de uns contra outros" (p. 72). Expõe então sua opinião sobre a questão central desse capítulo: "quem ama e sempre amou a História não está, nem nunca esteve em crise. Da minha parte, eu nunca estive em crise por causa dela, muito pelo contrário, ela sempre me causou um imenso prazer, o verdadeiro prazer de conhecer" (p. 83). 
No capítulo seguinte, o autor afirma que a História é fundamental para as relações cotidianas e amplia as possibilidades de sua compreensão, apresentando questões relevantes para o (a) leitor (a) se questionar e pensar sobre a "crise" dessa disciplina. Costa vai além das explicações consolidadas que concerne à função da História dentro da academia, abrindo assim um leque referente ao papel da História e do historiador. Desta maneira, chama a atenção para a ressignificação da escrita.

No último capítulo dessa seção, o autor analisa crônicas hebraicas e cristãs, por meio de um tema muito debatido na atualidade, a saber, o antijudaísmo. Sabe-se que no decorrer dos períodos históricos há episódios marcados por acontecimentos nem sempre favoráveis a determinados grupos. Nesse trecho da obra, o autor menciona as primeiras perseguições dos judeus, mostra a resistência franca contra este povo e apresenta sucintamente a relação da comunidade judaica com a Igreja Católica e as Cruzadas. Por fim, Costa trata de vários massacres sofridos por esse povo, revelando os rastros dos ressentimentos e preconceitos com o outro ao longo da História.

Na seção Literatura, Costa se debruça sobre as Sete Artes Liberais (c. 13041307), de Dante Alighieri, em que o poeta por meio da alegoria trabalha filosoficamente o tema das Artes Liberais nos complexos e "imaginários céus da Astrologia". O autor discorre sobre a poesia, a filosofia e o amor de modo reflexivo e crítico, bem como tece comentários, acerca do uso da poesia pelos medievos em seu trato com a ciência e a filosofia.

Em seguida, o autor aborda a relação entre sonho e história, a partir da obra $O$ sonho (1399), de Bernat Metge, trazendo uma reflexão filosófica a respeito de sua relevância para a sociedade medieval. Com base ainda na obra de Metge e na novela Curial e Guelfa (c. 1460), Costa apresenta a condição feminina sobre a perspectiva dos homens, com destaque para opressão sofrida por elas, para sua personalidade medieval e a para a voz das mulheres nesta obra. Diz o pesquisador: “[...] nela são as mulheres as verdadeiras protagonistas do enredo" (p. 176).

Na penúltima seção, intitulada Filosofia, o autor escreve sobre o Inferno, uma temática indispensável para o entendimento do imaginário do homem e da mulher medievais. Diante disso, deparamo-nos com dois espaços essenciais para a compreensão de como pensavam e viviam os habitantes deste período e de suas perspectivas em relação ao Paraíso e o Inferno. A preocupação com destino após a morte era uma 
indagação no medievo, já que a Igreja Católica, com a sua doutrina, levava os fiéis a crer que o principal objetivo dos homens era aproximar-se do Reino Celeste (ZIERER, 2013, p. 31).

Costa analisa a visão sobre o Inferno na ótica do filósofo Ramon Llull (12321316), o qual dedicou algumas de suas obras ao Além medieval. Para Costa, sem "[...] esse incisivo pano de fundo imagético, perspectiva transcendental, não é possível compreender a mentalidade medieval (grifo do autor, p. 190). Se na Contemporaneidade, e portanto, com o crescimento da laicização a descrição do Inferno ainda desperta medo e tormenta, para uma parcela da sociedade medieval, por sua vez, esse espaço era uma arma utilizada para regular o comportamento humano.

No capítulo seguinte, o autor analisa a terceira parte do Tratado da Obra dos Dias, de Teodorico de Chartres (c.1155), texto em que predomina uma abordagem filosófica acerca do criador, sob a perspectiva cristã. Para analisar a concepção da divindade nesse tratado, Costa retoma a filosofia clássica e se debruça sobre Platão, Sêneca dentre outros, que influenciaram o pensamento de Teodorico, nas questões relativas à esfera divina. Em sua investigação a respeito de Deus, Teodorico conciliaria: “[...] a verdade da Revelação cristã com a verdade científica de seu tempo (isto é, a das sete artes liberais). Para ele, não havia incompatibilidade entre a fé e a razão" (p. 222).

No último capítulo da seção Filosofia, Costa escreve sobre a disputa entre Bernardo de Claraval e Pedro Abelardo, não somente importantíssima no contexto medieval, mas portadora de reflexões interessantes no que se refere ao debate entre homens de natureza tão oposta. Nesse sentido, o autor apresenta o imenso sofrimento de Bernardo frente aos escritos de Pedro Abelardo. De acordo com Visões da Idade Média, Bernardo pediu que os bispos lessem nos escritos, pois "[...] estavam escritas coisas insólitas aos ouvidos e mentes católicas sobre a Santíssima Trindade, a geração do Filho e a precedência do Espírito Santo" (p. 228). Costa apresenta as interpretações da história que envolve Bernardo e Pedro Abelardo, na perspectiva histórica, filosófica e teológica. No mais, finaliza seu texto com o seguinte questionamento: "Até quando distorceremos a Histórica?” (p. 248).

No capítulo que abre a seção Artes, Costa discorre sobre as representações da vida camponesa na arte de Benedetto Antelami (c. 1150-1230). Essa arte dava vida às 
estações, às colheitas, à labuta do jovem e robusto camponês medieval. Costa ressalta que nessa produção artística há a presença do estilo românico provençal, algo presente nas obras de Antelami. Costa destaca que "[...] a história do campo, do campesinato, é a história de um mundo social quase sem história” (p. 256).

No capítulo seguinte, Costa realiza um estudo das representações do corpo no Retábulo de São João Batista (1425-1430), de Bernat Martorell. Analisa as expressões faciais, os gestos, as mãos, os detalhes de uma verdadeira obra de arte, que parecem ganhar movimento e vida diante de quem a contempla, diante dos sentimentos de medo, admiração, tristeza, dor, alegria e assombro. O penúltimo capítulo da seção Artes, Costa faz uma análise histórica do episódio bíblico de Susana e os anciãos, um texto interessante que versa sobre a contemplação da beleza.

No capítulo que encerra essa seção, o autor chama a atenção dos (as) leitores (as) e historiadores (as) para algo que ele define como importante, pois, quem se dispõe a pesquisar dada temática torna-se imperativo ter "paixão", afinco, seriedade e não omitir os fatos. Costa ressalta a relevância de se livrar das armadilhas da seleção viciada dos textos, e o cuidado ao querer "ressuscitar" o passado, já que "[...] para se fazer uma boa e apaixonada História, o historiador deve sair de si mesmo, deve se tornar acessível e ir ao encontro do outro" (p. 325). Além disso, quem escreve tem que ter maturidade, saber observar e analisar a cultura de cada época, pois “[...] a História é para maduros" (p. $330)$.

Costa mantém e dá sequência à estrutura do livro anterior, intitulado Impressões da Idade Média, outra coletânea de artigos, fruto do seu trabalho intenso como pesquisador. A organização do livro contou com o auxílio de alguns dos seus alunos, que o ajudaram na escolha dos artigos e e na seleção dos textos que viriam a compor as quatro divisões da obra: História, Literatura, Filosofia e Artes, que foram divididas em quatro temas: História, Literatura, Filosofia e Artes. O autor coloca em prática, como já havia afirmado em outro texto, que a História pode extrapolar os seus limites através de áreas diversas: "Não só a Política, não só a Economia, mas a História conceitual, a Arqueologia, a Literatura, a Artes, o Clima, o Corpo, enfim, o tempo, em todas as suas ricas contradições, diversidades e paradoxos" (COSTA, 2016, p. 304, grifos do autor).

$\mathrm{O}$ autor aborda o que considera os principais temas que fazem parte da sua trajetória acadêmica. Deste modo, apresenta a sua perspectiva sobre a História, a 
sociedade e a cultura medieval, dentre outras temáticas que nos ajudam a compreender como foi forjada a sociedade ocidental. Os textos reunidos nesta coletânea de artigos têm em comum a preocupação de mostrar as inúmeras formas de interpretar o passado, assim como de compartilhar o conhecimento histórico, fruto de um trabalho árduo e minucioso, levado a cabo por meio de diversas fontes.

Sem dúvida, as reflexões do professor Ricardo da Costa contribuem para novas visões sobre a Idade Média, já que muitos categorizaram esse período como "Idade das Trevas", negando neste a produção de conhecimentos, e a existência da cultura, do amor etc. Tais interpretações conservadoras apontavam a Igreja como detentora do saber, acusando a de esconder e barrar a ciência, com o intuito de explorar e manter os homens e mulheres medievais na ignorância. Infelizmente, muitos ainda são influenciados por essa visão preconceituosa.

Ademais, ao discorrer sobre o começo de sua trajetória acadêmica, não economiza críticas em relação à academia. Costa via-se como "um bom rebelde "pósaborrescente" e fala das "centenas de 'leitores de orelha' e de resenhas de livros e que nunca leram um livro até o fim” (p. 63). A nosso ver, a afirmação do autor é parcialmente justificável e Costa recai em generalizações. Sabe-se que no Brasil, marcado pelas diversas desigualdades, muitas pessoas carecem de incentivo e condições de levar os estudos adiante, porém isso não é uma condição de escolha, mas fruto da realidade de miséria e falta de recursos.

O autor também fala da importância de relacionar o texto e imagem, sempre, no entanto, com sensibilidade e rigor. Além das ponderações aqui feitas, esta resenha é um convite à leitura da obra completa, para que os leitores tirem suas próprias conclusões e construam as suas próprias intepretações. É nesse sentido que o livro Visões da Idade Média, torna-se uma leitura indispensável para todos aqueles que pesquisam o período medieval, assim como todos (as) que são amantes do conhecimento e admiradores dessa época multifacetada e rica de transformações, conhecida como Idade Média. 


\section{Referências}

BLOCH, Marc. A Apologia da História ou o Ofício do Historiador. Rio de Janeiro: Jorge Zahar, 2001.

COSTA, Ricardo da. As múltiplas Idades Médias de Jacques Le Goff (19242014). Brathair, São Luís, (UEMA), v. 16, n. 2, p. 303-314, 2016.

COSTA, Ricardo da. Impressões da Idade Média. São Paulo: Livraria Resistência cultural, 2017.

FRANCO JÚNIOR, Hilário. A Idade média: nascimento do ocidente, São Paulo: Brasiliense, 2001.

LE GOFF, Jacques. O Imaginário Medieval. Lisboa: Estampa, 2004.

ZIERER, Adriana. Da ilha dos bem-aventurados à busca do Santo Graal. São Luís: Ed. UEMA, 2013.

\section{Notas}

\footnotetext{
${ }^{1}$ Doutoranda em História pelo Programa de Pós-Graduação em História e Conexões Atlânticas: culturas e poderes (PPGHIS), da UFMA, sob financiamento Fundação de Amparo à Pesquisa e ao Desenvolvimento Científico e Tecnológico do Maranhão (FAPEMA). Mestra em História, Ensino e Narrativas pelo programa de Pós-Graduação em História, Ensino e Narrativas (PPGHIST), UEMA; licenciada em História (UEMA); licenciada em Pedagogia e Bacharela em Teologia pela FATEH.
} 